論文

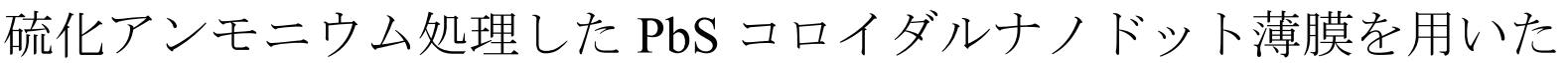 電界効果トランジスタ†
}

竹市 祐実* 三谷 展弘*

宇野 和行** 田中 一郎**

\section{Field-Effect Transistors Based on PbS Colloidal Nano-Dot Films Treated with Ammonium Sulfide Solution}

by

\author{
Yumi TaKeIchi*, Nobuhiro Mitani*, Kazuyuki UnO** and Ichiro TANAKA**
}

We fabricated field-effect transistors (FETs) using ammonium sulfide-treated PbS colloidal nano-dot (CND) films. After the ligand molecules were removed from the CNDs by the ammonium sulfide treatment, many cracks were observed in the atomic force microscope image of the PbS ND monolayer that was formed by horizontal lifting method. Those cracks were filled and almost disappeared after we repeated the formation of the PbS CND monolayer and removal of the ligand molecules for three times. The FETs fabricated with the cracked PbS ND films exhibited serious bias stress effect and very low hole mobility of $5.6 \times 10^{-5} \mathrm{~cm}^{2} \mathrm{~V}^{-1} \mathrm{~s}^{-1}$, which were attributed to the carrier traps existing on the NDs surface. On the other hand, the carrier mobility of the FETs with the crack-free PbS ND films was improved to be $1.1 \times 10^{-3} \mathrm{~cm}^{2} \mathrm{~V}^{-1} \mathrm{~s}^{-1}$ because the cracks were filled and the trap density was significantly reduced.

\section{Key words:}

PbS colloidal nano-dot, Ammonium sulfide, Ligand removal, Thin films, Field-effect transistors, Carrier mobility, Bias stress effect, Carrier traps

\section{1 緒言}

半導体コロイダルナノドット(CND)は, Fig. 1 の模式図 に示すように直径数ナノメートルの半導体微結晶（コア） とその表面に配位結合した有機分子（有機配位子）から 成るナノ材料である. ${ }^{1)}$ 有機化学的手法によって溶液中 で合成され，サイズ均一性が高く，溶媒に分散可能であ るため，印刷法などの溶液プロセスを用いて低温で成膜 できるという特長があり，低コストでフレキシブルな（光） 電子薄膜デバイスへの応用が期待されている. 半導体 CND の有機配位子としては, 溶媒への分散性を高めるた めに, トリ-n-オクチルホスフィンオキシドやオレイン酸 などの長い分子（分子長 1.5 2 nm）が使われている. し かし, これらの有機分子は絶縁性が高いため, 半導体 CND の薄膜を作製しても CND 閔のキャリア輸送が難しく，そ のままではデバイスへの応用はできない。また，短い有 機分子を配位子としても溶媒への分散性が悪くなり， CND が凝集してしまう問題が生じる.

そこで，半導体 CND の薄膜を形成した後に，その配位 子を短い分子に交換することによって CND 間の距離を狭 めてキャリア移動を可能にし, 電界効果トランジスタ (FET) を作製する試みが行われてきた. ${ }^{2) ~ 9)}$ 例えば, D. V. Talapin ら ${ }^{2)}$ はオレイン酸を配位子とした PbSe CND 薄膜 を濃度 $1 \mathrm{M}$ のヒドラジンのアセトニトリル溶液で処理し, それを用いて電界効果トランジスタ $(\mathrm{FET})$ を作製した結
果， $0.5 \mathrm{~cm}^{2} \mathrm{~V}^{-1} \mathrm{~s}^{-1}$ 程度のキャリア移動度が得られたことを 報告している。しかし, ヒドラジンは毒性や引火性が強 く実用面では好ましくない。また, エタンジチオール (EDT)などの短い有機分子に配位子を交換した PbS CND 薄膜を活性層に, イオン液体をゲート誘電体層に用いた FET が報告されている. ${ }^{5)}$ ゲート容量が非常に大きいので, $1 \mathrm{~V}$ 程度のゲート電圧でも面密度が $10^{14} \mathrm{~cm}^{-2}$ オーダーの 高密度なキャリアがチャネル層に蓄積されるためにキャ リアトラップが埋められ, われわれが目標とするレベル の $1 \mathrm{~cm}^{2} \mathrm{~V}^{-1} \mathrm{~s}^{-1}$ を越える高いキャリア移動度が得られたこ とが報告されているものの，イオン移動による分極を利 用しているので周波数特性の面からは実用的ではないと 考えられる.

さらに，半導体 CND 薄膜を熱処理することによって配 位子を脱離させるとともにナノ結晶同士を「融合」させ て，電子移動度が 20 $\mathrm{cm}^{2} \mathrm{~V}^{-1} \mathrm{~s}^{-1}$ 程度の FET を作 製した例も報告されてい るが，7)処理温度が 150 250 ${ }^{\circ} \mathrm{C}$ と高いため, 汎 用プラスチック基板を用 いるフレキシブルなデバ イスには適用できない.

一方, 半導体 CND 薄膜

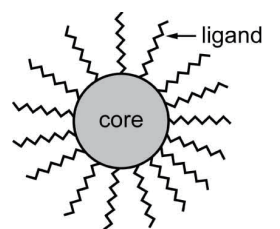

Fig.1 Schematic illustration of a colloidal nano-dot consists of a core crystal and ligand molecules.

$\dagger$ 原稿受理 平成 30 年 2 月 2 日 Received Feb. 2, 2018 C2018 The Society of Materials Science, Japan

* 和歌山大学 システム工学部 ₹ $640-8510$ 和歌山市栄谷

Faculty of Systems Engineering, Wakayama University, Sakaedani, Wakayama 640-8510.

** 正 会 員 和歌山大学 システム工学部 テ640-8510 和歌山市栄谷

Faculty of Systems Engineering, Wakayama University, Sakaedani, Wakayama 640-8510. 


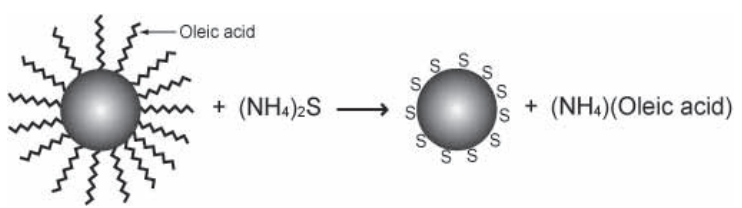

Fig.2 Schematic illustration of the ligand removal process by $\left(\mathrm{NH}_{4}\right)_{2} \mathrm{~S}$ treatment.

の配位子を除去することによってコア同士が結合した薄 膜を作製する研究も報告されている. H. Zang ら ${ }^{10)}$ は, オレイン酸を配位子に持つ PbS CND 薄膜を硫化アンモニ ウム溶液で処理すると, Fig. 2 に示すようにオレイン酸が 除去されるとともに $\mathrm{PbS}$ コア表面に $\mathrm{S}$ 原子が配位し，さ らにそれらの $\mathrm{S}$ 原子を介して隣接した $\mathrm{PbS}$ コア同士が結 合することを見出した，その結果，励起子吸収やフォト ルミネッセンスのピークが長波長側にシフトすることも 報告された。この方法は有機配位子を介さずにコア同士 を結合させることが可能なので，キャリア輸送に有利で あると考えられる。

本研究ではこの点に着目し， 1 層ごとの成膜が可能な 水平付着法 ${ }^{11)}$ によって作製した $\mathrm{PbS} \mathrm{CND}$ の単粒子層を 硫化アンモニウム処理してオレイン酸配位子を除去する プロセスの検討とそれを利用した FET の作製を行った.

\section{2 実験}

本研究では, Evident Technologies 社製のオレイン酸を 配位子とする PbS CND（コア径 $2.3 \mathrm{~nm}$ ）を用いて，水平 付着法によりその単粒子層を作製した。まず，トラフに 水を張り, $0.5 \mathrm{wt} \%$ の PbS CND クロロホルム溶液を水面上 に展開させた（Fig. 3(a)）. クロロホルムの蒸発によって, 水面で PbS CND が 2 次元的に凝集し，単粒子層が形成さ れる (Fig. 3(b))．その単粒子層に上から基板を接触させ ると（Fig. 3(c)），基板上に PbS CND 単粒子層が移される (Fig. 3(d)). 今回は, 厚さ $300 \mathrm{~nm}$ の熱酸化 $\mathrm{SiO}_{2}$ 膜付き $\mathrm{n}^{+}-\mathrm{Si}(001)$ 基板を用意し，付着力を高める為にその表面を (3-Mercaptopropyl) trimethoxysilane (MPTMS)処理して用い た ${ }^{10)}$.

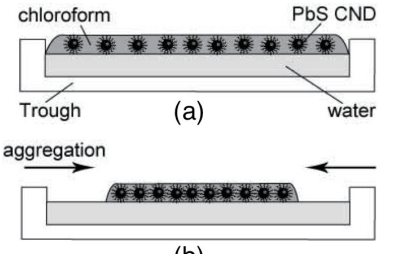

(b) substrate

n.

(c)

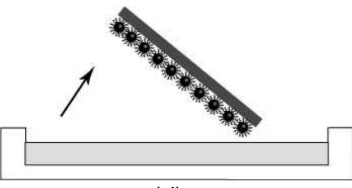

(d)

Fig.3 Fabrication process of CND monolayer film by horizontal lifting method.
次に, 濃度が $0.04 \mathrm{M}$ の 硫化アンモニウムのメタ ノール溶液中に $\mathrm{PbS} \mathrm{CND}$ 単粒子膜試料を 2 秒間浸 漬させ，硫化アンモ二ウ ム処理を行った。 その後, 脱離したオレイン酸分子 を除去するためにメタノ

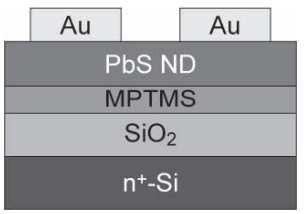

Fig. 4 Schematic of the PbS ND FETs.
ールで 5 秒間リンスした。この工程を 1 3 回繰り返して 形成した $\mathrm{PbS}$ ナノドット薄膜にメタルマスクを介して金 のソース／ドレイン電極を真空蒸着し, FETを作製した. チャネル長は 17 - $63 \mu \mathrm{m}$ ，チャネル幅は $2 \mathrm{~mm}$ である.こ のようにして作製した FET の模式困を Fig. 4 に示す. FET の特性は，半導体パラメータアナライザを用いて，1 Pa 程度の真空中で光が当たらない状態で測定した. 出力特 性はゲート電圧 $\left(V_{\mathrm{G}}\right)$ を $10 \mathrm{~V}$ ずつ変化させながら測定した。 またノンドープ $\mathrm{Si}$ 基板上に同様にして PbS CND 単粒子 膜を作製し，硫化アンモニウム処理の前と後でフーリエ 変換赤外吸収(FTIR)スペクトルを測定した。

\section{3 結果および考察}

作製した PbS CND 単粒子層の硫化アンモニウム処理前 後の FTIR スペクトルを Fig. 5 に示す. $2955 \mathrm{~cm}^{-1}$ 付近, 2920 $\mathrm{cm}^{-1}$ 付近および $2850 \mathrm{~cm}^{-1}$ 付近にピークを持つブロードな 吸収はオレイン酸分子の C-H 伸縮振動によるものである. 12) これらのピークは 2 秒間の処理で大きく減衰し，配位 子が除去されたことを反映していると考えられる。

次に，硫化アンモニウム処理前の $\mathrm{PbS}$ CND 単粒子層の AFM 像を Fig. 6(a)に示す.この像では個々の PbS CND を 分解して観察することはできないが，広い範囲でほぼ均 一に PbS CND 薄膜が形成されていると考えられる.また, 挿入困は図中の A-B 間の断面プロファイルを示す. この プロファイルから凹部の段差は約 $5 \mathrm{~nm}$ であることが分か る。これは配位子を含む $\mathrm{PbS}$ CND の直径約 $6 \mathrm{~nm}$ に近い 值であるため，被覆率が高い $\mathrm{PbS} \mathrm{CND}$ 単粒子層の形成が 確認できたと考えられる．Fig.7(a)にその模式図を示す.

次に, PbS CND 単粒子層を硫化アンモニウム処理して 配位子を除去した後の AFM 像を Fig. 6(b)に示す.この像 からは，配位子が除去された膜に多数のクラックが生じ たことが分かる。これらは，PbS CNDの配位子が除去さ れて残ったコア間に隙間が生じ，さらにコア同士が基板 上で凝集したために形成されたものと考えられる. その

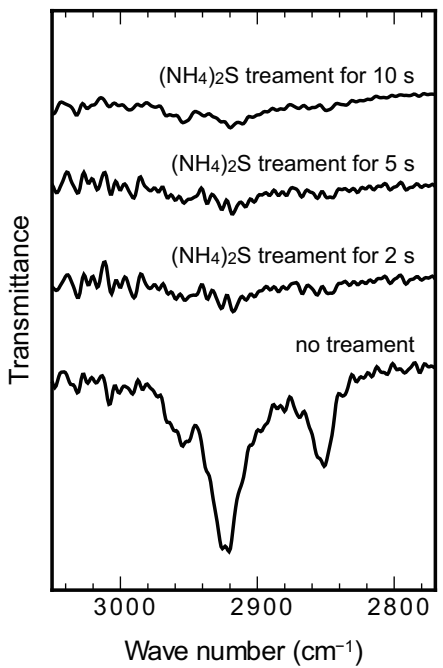
treated $\mathrm{PbS}$ CND films.
Fig. 5 FTIR spectra of $\left(\mathrm{NH}_{4}\right)_{2} \mathrm{~S}$ 模式図を Fig. 7(b)に示す. 同様の結果は, PbS CND のスピンコート薄膜の 配位子を除去した場合 10) やPbSe CNDのオレイ ン酸配位子を短い有機 分子に交換した場合な どにも報告されている. 13)このように配位子が 除去された単粒子層（薄 膜）を今後は PbS ND 単 粒子層（薄膜）と呼ぶ. $\mathrm{PbS}$ ND 単粒子層上に, 再度水平付着法で $\mathrm{PbS}$

CND 単粒子層を形成 して硫化アンモニウ 

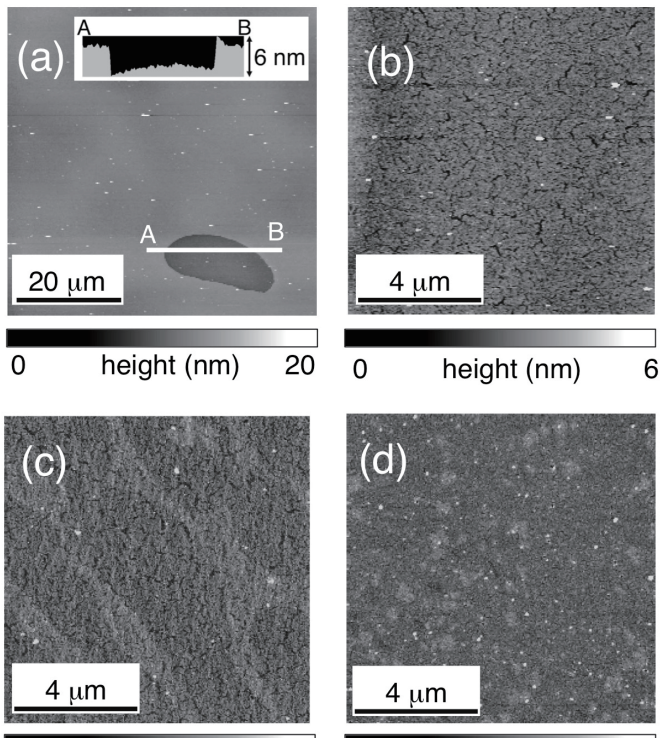

0 height (nm) 15 0 height $(\mathrm{nm}) \quad 10$

Fig. 6 AFM image of the PbS CND monolayer (a) before and (b) after $\left(\mathrm{NH}_{4}\right)_{2} \mathrm{~S}$ treatment, and that of the $\mathrm{PbS}$ ND layers after repeated CND deposition and ligand removal for (c) two and (d) three times.

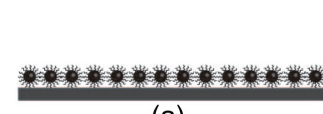

(a)

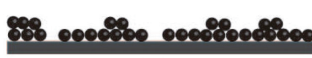

(c)

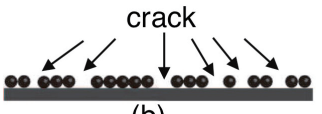

(b)

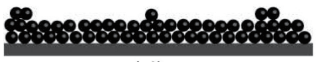

(d)
Fig. 7 Schematic illustration of the model that explains the observed AFM images shown in Fig. 6.

ム処理したときの AFM 像を Fig. 6(c)に示す. まだクラッ クが観察されるが，2 層目と思われる PbS ND 層が部分的 に形成されていることが分かる，さらに，この上に 3 回 目の水平付着法による $\mathrm{PbS} \mathrm{CND}$ 単粒子層形成と配位子の 除去を行った後の PbS ND 薄膜の AFM 像を Fig. 6(d)に示 す。この像ではクラックがほぼ埋まった薄膜上に，大き さがサブミクロン程度の「島」が点在している。これら の「島」の被覆率は約 $20 \%$ ある。したがって，PdS ND の 2 層目までがほぼ埋まり, 3 層目が部分的に形成されて いるのではないかと考えられる. 2 回目および 3 回目の水 平付着と配位子除去の各段階でどのように PbS ND 薄膜 が形成されたかを示すモデルを Fig. 7(c)-7(d)の模式図に 示す.

水平付着法により形成した PbS CND 単粒子層およびそ の配位子を脱離した $\mathrm{PbS} \mathrm{ND}$ 単粒子層にソース／ドレイ ン電極を蒸着して作製した FET では充分なドレイン電流 が得られず，トランジスタ特性が示されなかった。これ は，PbS CND 単粒子層の場合は，オレイン酸配位子の絶 縁性が高かったため, また, PbS ND 単粒子層の場合は, 多数のクラックによってキャリア移動が妨げられたため と考えられる。

次に，水平付着法による薄膜形成と硫化アンモニウム 処理による配位子脱離を 2 回繰り返して作製したPbS ND
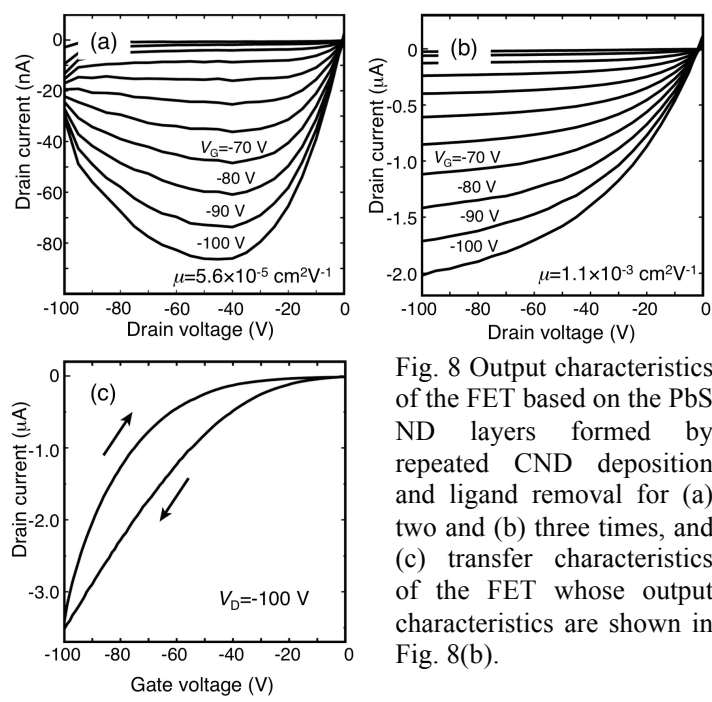

Fig. 8 Output characteristics of the FET based on the PbS ND layers formed by repeated $\mathrm{CND}$ deposition and ligand removal for (a) two and (b) three times, and (c) transfer characteristics of the FET whose output characteristics are shown in Fig. 8(b).

薄膜を使用した場合は, Fig. 8(a)に出力特性を示すように $\mathrm{p}$ 型の FET 特性が得られた. ドレイン電流の大きさは 10 $\mathrm{nA}$ オーダーで, ドレイン電圧が-45 V 程度のときに最大 になっている．このときのドレイン電流のゲート電圧依 存性から算出したキャリア移動度は $5.6 \times 10^{-5} \mathrm{~cm}^{2} \mathrm{~V}^{-1} \mathrm{~s}^{-1}$ で ある，そこからドレイン電圧が（負で）大きくなると逆 にドレイン電流は減少しているが，これはいわゆるバイ アスストレスの影響と考えられる。 バイアスストレス効 果としては，水素化アモルファスシリコン(a-Si:H) FET に おいて, ゲート電圧の印加によりチャネル内に形成され たキャリアが，ゲート絶縁膜中や a-Si:H 膜中の局所卜ラ ップに捕獲され, 伝導に寄与しなくなるためドレイン電 流が減少し，それに伴ってしきい值電圧もシフトすると 報告されている. ${ }^{14), 15)}$ また, 有機 FET の場合も同様にゲ 一ト電圧を印加することによるドレイン電流の減少やし きい值シフトが多数報告されており, やはりキャリアが チャネル近傍のトラップに捕獲されてしまうためと言わ れている. 16) 18) 例えば，ペンタセン FET では大気中の 水分の影響によって形成されるキャリアトラップが原因

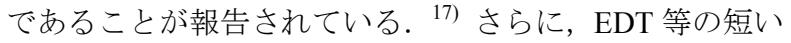
有機分子に配位子交換した PbSe ND 薄膜を用いた FET で は，ゲート電圧の印加によって生じたドレイン電流が, キャリアトラップの影響によって 5 から 7 秒程度の時定 数で指数関数的に減少することが報告されている. 13), 19) 今回の硫化アンモニウム処理によって配位子が除去され た PbS ND 薄膜でも，ND 表面に残っている欠陥がキャリ アトラップとなったためにドレイン電流が減少したと考 えられる。

$\mathrm{PbS}$ CND の水平付着と硫化アンモニウム処理を 3 回繰 り返して作製した PbS ND 薄膜を使用した FET では Fig. 8(b)に示す出力特性が得られた. ドレイン電流は最大 $2 \mu \mathrm{A}$ 程度に増加し, キャリア移動度は $1.1 \times 10^{-3} \mathrm{~cm}^{2} \mathrm{~V}^{-1} \mathrm{~s}^{-1}$ に向 上した。 また，ドレイン電流は，ドレイン電圧が増加す るにつれてほぼ飽和し，バイアスストレスの影響は見ら れない。これは，PbS ND 薄膜のクラックがほぼ埋められ たためにキャリア輸送が容易になったと同時に表面積の 
減少によりキャリアトラップも減少したためと考えられ る.しかし，Fig. 8(c)に示すこの素子の伝達特性には大き なヒステリシスが存在するため，まだキャリアトラップ の影響が大きいと考えられる. S. Hong ${ }^{20)}$ は, CdSe/ZnS CND 溶液を用いた実験で，同溶液にメルカプトエタノー ルを加えると PLの時間的強度変動が減少することを報告 し，これはメルカプトエタノールのチオール基が供給す る電子が $\mathrm{CdSe} / \mathrm{ZnS}$ CND 表面のトラップ準位を埋めるた めであるとしている。したがって, PbS ND 薄膜の場合も このような処理を加えることによってキャリアトラップ を減少させ，さらに移動度を向上させることができると 期待される.

\section{4 結 言}

$\mathrm{PbS}$ CND の単粒子層形成と硫化アンモニウム処理を複 数回繰り返すことによって, 配位子の除去によって生じ たクラックを減少させて緻密な PbS ND 薄膜を作製する ことができた。ささらに，これらの薄膜を用いて FET を作 製したところ，クラックが埋まったことによるトラップ の減少によってキャリア移動度が $1 \times 10^{-3} \mathrm{~cm}^{2} \mathrm{~V}^{-1} \mathrm{~s}^{-1}$ 程度ま で向上した。今後，より高い移動度を実現するためには さらにキャリアトラップを減少させる必要がある.

本研究は JSPS 科研費 JP15K05986 の助成を受けました.

1) C. B. Murray, D. J. Norris and M. G. Bawendi, "Synthesis and characterization of nearly monodisperse CdE (E=S, Se, Te) semiconductor nanocrystallites", Journal of The American Chemical Society, Vol.115, No.19, pp.8706-8715 (1993).

2) D. V. Talapin and C. B. Murray, "PbSe nanocrystal solids for $\mathrm{n}^{-}$and $\mathrm{p}^{-c h a n n e l}$ thin film field-effect transistors", Science, Vol.310, Issue 5745, pp.86-88 (2005).

3) J.-S. Lee, E. V. Shevchenko and D. V. Talapin, "Au-PbS core-shell nanocrystals: plasmonic absorption enhancement and electrical doping via intra-particle charge transfer", Journal of The American Chemical Society Vol.130, No.30, pp.9673-9675 (2008).

4) D. Zhitomirsky, M. Furukaea, J. Tang, P. Stadler, S. Hoogland, O. Voznyy, H. Liu and E. H. Sargent, "N-type colloidal-quantum-dot solids for photovoltaics", Advanced Materials Vol.24, Issue 46, pp.6181-6185 (2012).

5) S. Z. Bisri, C. Piliego, M. Yarema, W. Heiss and M. A. Loi, "Low driving voltage and high mobility ambipolar field-effect transistors with PbS colloidal nanocrystals", Advanced Materials, Vol.25, Issue 31, pp.4309-4314 (2013).

6) M. S. Kang, J. Lee, D. J. Norris and C. D. Frisbie, "High carrier densities achieved at low voltages in ambipolar PbSe nanocrystal thin-film transistors", Nano Letters, Vol.9, No.11, pp.3848-3852 (2009).
7) Z. M. Norman, N. C. Anderson and J. S. Owen, "Electrical transport and grain growth in solution-cast, chloride-terminated cadmium selenide nanocrystal thin films", ACS Nano, Vol.8, No.7, pp.7513-7521 (2014).

8) W-k. Koh, S. R. Saudari, A. T. Fafaman, C. R. Kagan and C. B. Murry, "Thiocyanate-capped PbS nanocubes: ambipolar transport enables quantum dot based circuits on a flexible substrate", Nano Letters, Vol.11, No.11, pp.4764-4767 (2011).

9) D. M. Balazs, M. I. Nugraha, S. Z. Bisri, M. Sytnk, W. Heiss and M. A. Loi, "Reducing charge trapping in $\mathrm{PbS}$ colloidal quantum dot solids", Applied Physics Letters, Vol.104, No.11, pp.112104-1-112104-4 (2014).

10) H. Zhang, B. Hu, L. Sun, R. Hovden, F. W. Wise, D. A. Muller and R. D. Robinson, "Surfactant ligand removal and rational fabrication of inorganically connected quantum dots", Nano Letters, Vol.11, No.12, pp.5356-5361 (2011).

11) K. Fukuda, H. Nakahata and T. Kato, "Monolayer and multilayers of anthraquinone derivatives containing long alkyl chains", Journal of Colloid and Interface Science, Vol.54, No.3, pp.430-438 (1976).

12) J. Kumanotani, "Infrared and near infrared spectroscopic analysis", Journal of Oleo Science, Vol.11, No.11, pp.577-590 (1962).

13) J. M. Luther, M. Law, Q. Song, C. L. Perkins, M. C. Beard and A. L. Nozik, "Structural, optical, and electrical properties of self-assembled films of $\mathrm{PbSe}$ nanocrystals treated with 1,2-ethanedithiol", ACS Nano, Vol.2, No.2, pp.271-280 (2008).

14) M. J. Powell, "Charge trapping instabilities in amorphous silicon-silicon nitride thin-film transistors", Applied Physics Letters, Vol.43, No.6, pp.597-599 (1983).

15) M. J. Powell and S. C. Deane, "Microscopic mechanism for creation and removal of metastable dangling bonds in hydrogenated amorphous silicon", Physical Review B, Vol.66, No.15, pp.155212-1-155212-11 (2002).

16) U. Zschieschang, R. T. Weitz, K. Kern and H. Klauk, "Bias stress effect in low-voltage organic thin-film transistors", Applied Physics A, Vol.95, No.1, pp.139-145 (2009).

17) C. Goldmann, D. J. Gundlach and B. Batlogg, "Evidence of water-related discrete trap state formation in pentacene single-crystal field-effect transistors", Applied Physics Letters, Vol.88, No.6, pp.063501-1-063501-3 (2006).

18) T. Sekitani, S. Iba, Y. Kato, Y. Noguchi and T. Someya, "Suppression of DC bias stress-induced degradation of organic field-effect transistors", Applied Physics Letters, Vol.87, No.7, pp.073505-1-073505-3 (2005).

19) Y. Liu, M. Gibbs, J. Puthussery, S. Gaik, R. Ihly, H. W. Hillhouse and M. Law, "Dependence of carrier mobility on nanocrystal size and ligand length in PbSe nanocrystal solids", Nano Letters, Vol.10, No.5, pp.1960-1969 (2010).

20) S. Hong and T. Ha, "Near-complete suppression of quantum dot blinking in ambient conditions", Journal of The American Chemical Society, Vol.126, No.4, pp.1324-1325 (2004). 